\title{
nature
}

\section{The moment of truth for high-energy physics}

Governments on both sides of the Atlantic seem under-prepared to defend the Large Hadron Collider from its critics in the US Congress.

T he lengthy process whereby the United States Congress will, it is hoped, eventually provide funds for US participation in the Large Hadron Collider (LHC) at the European Laboratory for Particle Physics (CERN) has got off to an inauspicious start.

The trouble started in March when Joe Barton (Republican, Texas), in whose district sit the abandoned tunnels of the Superconducting Super Collider (SSC), pledged to do everything in his power, as he so vividly put it, to prevent "one thin dime from being spent on this".

It worsened two weeks ago, when the Science Committee of the House of Representatives - a forum normally sympathetic to both science and internationalism - voted to hold back $\$ 35$ million for the LHC pending clarifications from the US Department of Energy (DoE). James Sensenbrenner, chair of the Science Committee, has since visited CERN and returned with a lengthy wish list of modifications to the preliminary agreement which the DoE reached with CERN in February (see page 3).

Although European governments are not going to make a commitment to support some hypothetical, future US particle physics project, for example, it should not be beyond the wit of the DoE and CERN to satisfy Sensenbrenner. But the US administration must get squarely behind the project and sell it to the Congress.

In an influential report three years ago, Sidney Drell, deputy director of the Stanford Linear Accelerator Center, recommended that the United States should find resources from within its existing highenergy physics budget to participate in LHC. But he added an important proviso: without serious attention at the highest level - the White House - "international collaboration doesn't fly". Since then, the White House has been entirely silent on the issue. The administration has never bothered to explain to the American people that the sum to be spent on this project will not go to Switzerland, as Barton asserts, but will be spent at Fermilab and Brookhaven, and with American industry. It has not countered the pernicious fairy-tale that lack of foreign support killed the SSC - the culprits were budgetary pressures, regional tensions and managerial incompetence.

In the previous Congress, officials hinted that silence was indeed their strategy, on the grounds that presidential support would single out the LHC for attack from the Republican Congress. But now that the project is under attack in the Congress, it is time for Jack Gibbons, the president's science adviser, to muster his boss in its defence.

Fortunately, Sensenbrenner and his Democrat counterpart George Brown, who shares some of his concerns, both agree that this project should proceed. They are aware of its importance to US particle physics, which is barely off its knees from the SSC debacle and would be humiliated and crippled by withdrawal from the LHC.

What Sensenbrenner and Brown are less sure about is the ability of the DoE to negotiate a good deal. Sensenbrenner says that he got more information in a day's visit to CERN than the department had provided him in the previous two years. Federico Peña, the new energy secretary, could demonstrate his competence to the Congress and his commitment to the science community by striking a revised deal acceptable to both CERN and to the Science Committee.

International collaboration in science is extraordinarily difficult to sustain. Nationalistic forces, be they angry Texan congressmen or hard-pressed Germans, will always attack budgets at their weakest point - wherever money seems to go abroad. US government officials who recognize the economic sense of sharing the costs of the LHC, as well as the physicists who anticipate its fruits, had better prepare for a lengthy battle in its defence.

\section{Telegrams abused}

\section{Circulars intended to notify astronomers of new detections should not be used to stake researchers' claims.}

1 he International Astronomical Union (IAU) and the Smithsonian Astrophysical Observatory run an invaluable programme that rapidly distributes to astronomers around the world information on new and exciting astronomical sources. The intention is that the IAU circulars should be used to communicate positions and brightness of objects such as comets and supernovae, so that other astronomers can quickly confirm the data, or extend the observations to other wavelengths, in order to learn more about transient phenomena.

A flurry of circulars over the past six months or so threatens to overwhelm the administration of the office at Harvard University responsible for issuing them. Moreover, the purpose of the circulars is being subverted by some researchers seeking personal glory. These astronomers are submitting circulars that are miniature papers, containing interpretation and speculation, with the apparent intention of grabbing immediate publicity, without subjecting the work to the peer-review process that has evolved as the scientific community's means of policing itself. Others are submitting circulars reporting data that cannot be obtained by anyone else and are irrelevant to observations at any other wavelength.

The IAU circulars serve astronomers excellently when they report data with the intention of promoting scientific understanding. Gamma-ray bursters are a good example. Rapid, accurate positions of the bursts are essential to finding a counterpart at optical or radio wavelengths, as demonstrated very recently. But vital information could be delayed - or even lost - amid a flood of inappropriate circulars speculating about the nature of a counterpart.

Circulars should have but one role: discoverers of unusual phenomena alerting others to their discoveries. Astronomers should submit circulars that do no more than help others to make observations, and the Central Bureau for Astronomical Telegrams at Harvard should reject circulars that do not serve this purpose. 